\title{
Primary Research on Preparation and Properties of Shield Tail Sealing Grease
}

\author{
Jie Zhang ${ }^{1, a}$, Yongwei Wang ${ }^{1, b}$, Jinming Wang ${ }^{1, c}$, Fangjia Song ${ }^{1, d}$ and \\ Maoqian Yang ${ }^{1, e}$ \\ ${ }^{1}$ Shandong Academy of Building Research, Jinan 250031, China \\ ajessiezjie@163.com, ${ }^{b}$ yongweiwang@126.com, ${ }^{c}$ jnwangjm@sina.com, ${ }^{\mathrm{d}}$ song fang_jia@163.com, \\ yangmaogian@126.com
}

Keywords: preparation; properties; shield tail sealing grease; water-tightness under high pressure Abstract. In this paper, a type of shield tail sealing grease, composed of basic oil, thickening agent, lubricating grease thickener, lubricating grease, biodegradable fiber and inorganic fillers, was prepared by means of a physical mixing process. In addition, various properties such as density, cone penetration, water-tightness under high pressure, resistance to water spray, evaporation loss and anti-wear were studied. The results show that the shield tail sealing grease prepared under certain composition has relatively excellent properties. For the better samples, the density and cone penetration at the temperature of $25^{\circ} \mathrm{C}$ are respectively in the range of $1.28 \pm 0.02 \mathrm{~g} / \mathrm{cm}^{3}$ and $220-230$ $\mathrm{mm}$. No water leakage occurs for over $7 \mathrm{~min}$ under high pressure, and it means a good water-tightness under high pressure. Furthermore, the water-resistant stability, stable ability at high temperature and the ability of resisting wear are all well qualified.

\section{Introduction}

Shield technology, as a construction technology of fully mechanized excavation of underground tunnel, has been widely used at home and abroad in recent years because of the safety, high efficiency, small impact on the environment and strong anti-jamming capability [1-3]. It has got a wide application in some large-scale tunnel projects such as urban subway, river-crossing highway tunnels, and cross-ocean tunnels in China. Especially, subway construction in a great many cities is in full swing with the development of domestic infrastructure [4].

The shield technology follows an important technology which the shield machine develops, so shield tunneling machine is the main construction machinery. There is a relative slip between the shield and the installed pipe while the machine is tunneling. Given that, it is no doubt that the important task and key technology of shield tunneling is to avoid leakage. Shield tail sealing is an essential barrier which can isolate the shield machine from the surrounding ground $[5,6]$.

Therefore, it correspondingly appears a kind of product called shield tail sealing grease which is one of the indispensable supporting materials for shield tunneling of shield tunneling machine, with characteristics of waterproof-sealing and lubrication. The shield tail and mud can be effectively protected and insulated by shield tail sealing grease so that the shield can be successfully pushed forward. Besides, it can prevent corrosion and reduce the attrition on shield to some extent [5-7]. This requires that shield tail sealing grease must be of good water-tightness under high pressure, pumpability and mobility [8]. These performances are directly related to the quality and security of the whole tunnel and the shield machine.

Currently, the demand for shield tail sealing grease has been increasingly growing up with the construction of many urban rail transit in China. Meanwhile, more and more projects cross the rivers and lakes, and for the shield construction various complicated soil may occur [9]. Thus, the requirement for the sealing grease is obviously improved. There exist some general problems in domestic shield tail sealing grease, which has a certain gap with foreign advanced technology. For example, bad water-tightness or poor pumpability leads to serious leakage and even ground subsidence, unable to meet the requirements of engineering [10]. It is significant and essential to explore high-quality shield tail sealing grease. 
This study primarily investigates the preparation of shield tail sealing grease and the performance such as cone penetration, water-tightness under high pressure, mobility, resistance to water spray, evaporation loss and anti-wear are studied. It is hoped that this paper could o $\square$ er available data for further study and application of shield tail sealing grease and make a strong foundation for study more cost-effective shield tail sealing grease products.

\section{Experimental work}

Sample preparation. Industrial-grade raw materials such as basic oil (R1), thickening agent (R2), lubricating grease thickener (R3), lubricating grease (R4), biodegradable fiber with a suitable toughness and length (R5) and inorganic fillers (R6 and R7) are mainly used to prepare the shield tail sealing grease. In earlier study by the current authors, it was found that a probable composition of different raw materials, as is shown in Table 1. The percentage is in relation to prepared shield tail sealing grease by mass and the same as follows. In this study, a primary proportion of various raw materials are fixed on basis of the previous results given in Table 1. Then considering that the total percentage of raw materials is $100 \%$, flexible adjustment of the proportion is needed until we obtain the shield tail sealing grease with excellent performance in all aspects. The detailed matches are listed in Table 2.

Table 1 The round composition of raw materials [wt. \%]

\begin{tabular}{|c|c|c|c|c|c|c|c|c|}
\hline $\mathrm{R} 1$ & \multirow{2}{*}{$\frac{\mathrm{R} 2}{15-25}$} & \multicolumn{2}{|l|}{ R3 } & $\mathrm{R} 4$ & R5 & \multicolumn{2}{|c|}{ R6 } & $\mathrm{R} 7$ \\
\hline $8-15$ & & \multicolumn{2}{|c|}{$0.5-1.5$} & $10-15$ & $4-10$ & \multicolumn{2}{|c|}{$20-35$} & $20-30$ \\
\hline \multicolumn{9}{|c|}{ Table 2 Designed composition of raw materials [wt. \%] } \\
\hline & & & & & & & & \\
\hline rials & R1 & $\mathrm{R} 2$ & R3 & $\mathrm{R} 4$ & R5 & R6 & $\mathrm{R} 7$ & Total \\
\hline S0 & 8.7 & 22.7 & 1.0 & 12.3 & 6.0 & 33.3 & 16.0 & 100.0 \\
\hline $\mathrm{S} 1$ & 9.3 & 21.7 & 1.0 & 12.3 & 6.0 & 26.7 & 23.0 & 100.0 \\
\hline S2 & 11.0 & 20.0 & 1.0 & 12.3 & 6.0 & 25.0 & 24.7 & 100.0 \\
\hline S3 & 11.0 & 20.3 & 1.0 & 12.3 & 6.4 & 25.0 & 24.0 & 100.0 \\
\hline S4 & 11.0 & 20.3 & 1.2 & 12.3 & 6.4 & 24.8 & 24.0 & 100.0 \\
\hline S5 & 11.7 & 19.0 & 1.2 & 12.5 & 6.7 & 23.3 & 25.7 & 100.0 \\
\hline S6 & 12.8 & 19.0 & 1.2 & 11.7 & 6.7 & 20.0 & 28.7 & 100.0 \\
\hline S7 & 12.8 & 19.0 & 1.2 & 11.7 & 6.4 & 22.9 & 26.0 & 100.0 \\
\hline S8 & 13.5 & 19.0 & 1.2 & 11.7 & 6.3 & 22.9 & 25.5 & 100.0 \\
\hline S9 & 13.5 & 19.5 & 1.2 & 12.0 & 6.3 & 20.0 & 27.5 & 100.0 \\
\hline $\mathrm{S} 10$ & 13.8 & 19.3 & 1.2 & 12.0 & 7.0 & 20.7 & 26.0 & 100.0 \\
\hline
\end{tabular}

The preparation of shield tail sealing grease is a physical mixing process. $\mathrm{R} 2$ requires being heated to a certain temperature until it is completely dissolved before mixing. Firstly, R1 and R4 are mixed for about 15 minutes, and then $\mathrm{R} 2$ is all added into the previous formed mixture and mixed for 30 minutes. After that a half amount of R6 and R7 is added into it at the same time and mixed for 20 minutes. One third of R5 is added and stirred continually for 10 minutes, and the same procedure is repeated before putting the remaining R6 into the mixture and stirring for 10 minutes. R3 and the left amount of R7 are simultaneously introduced into the mixture and stirred for 15 minutes. Finally, the last R5 is added and all the mixture continue to mix for 1-2 hours to ensure a homogenous blend. The brief process flow is illustrated in Fig. 1. 


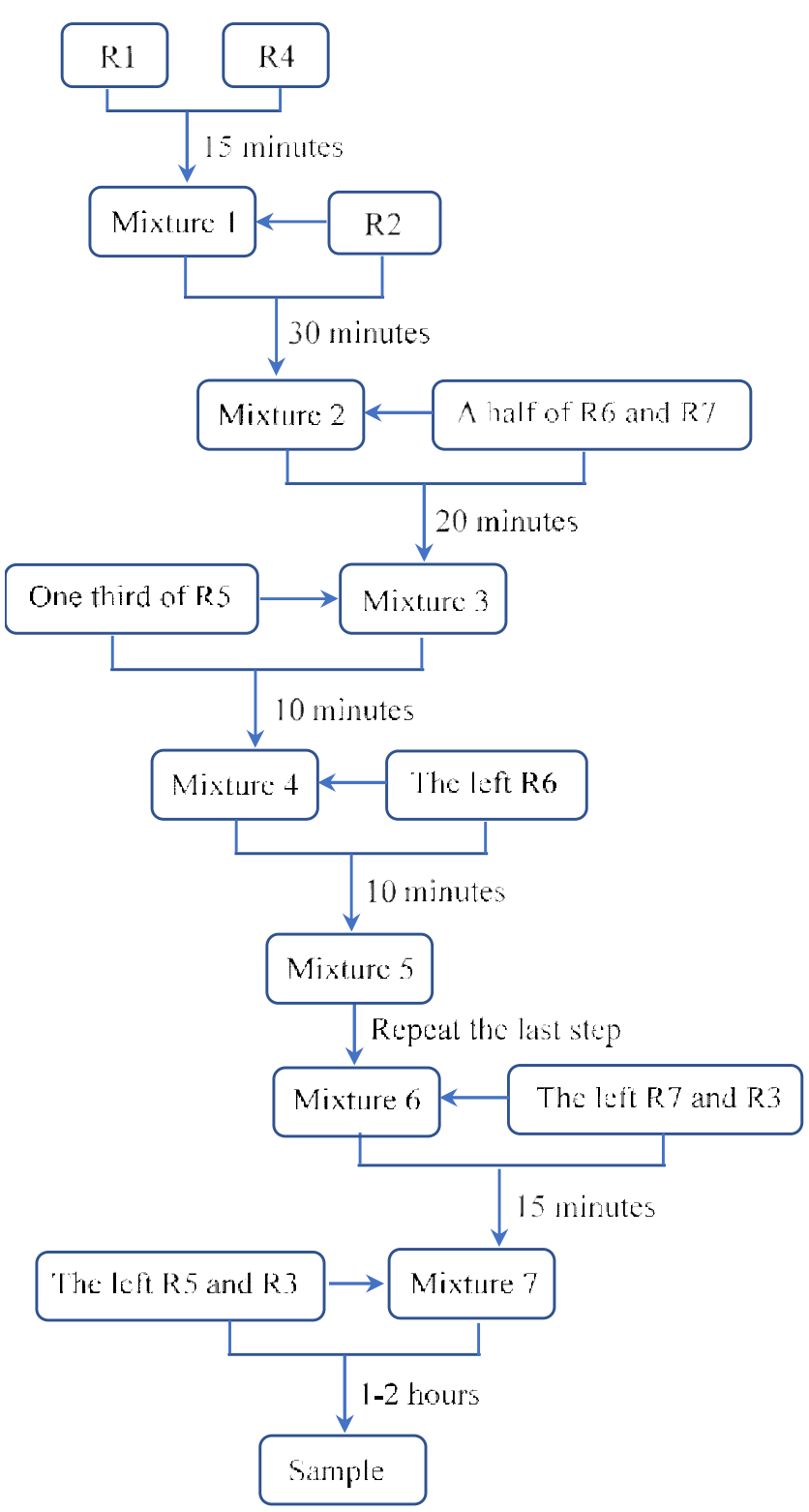

Fig. 1 Flow chart of shield tail sealing grease preparation process

Characterization. The densities $\left(25^{\circ} \mathrm{C}\right)$ were measured according to ASTM D1475-98 by a metal cup with the volume of $168 \mathrm{~cm}^{3}$. Consistency of the sealing grease at $25^{\circ} \mathrm{C}$ is characterized by cone penetration, which was conducted by a cone penetration tester (SYD-2801C, Shanghai Changji Geological Instrument co. LTD, China) per GB/T 269-91. For Water-tightness under high pressure, there is no uniform test method of seal oil and water pressure seal in domestic, at present. Through comparing anti-water pressure sealing device of different countries, and taking the actual use of the seal grease in the construction of domestic tunnel, self-assembled test equipment is successfully made, as is shown in Fig. 2. Besides, the workability and stability of grease directly under water spray are characterized by resistance to water spray, which was carried out by grease anti-water spray tester (BF-205, North Dalian Analytical Instrument co. LTD, China) based on ASTM D4049-2006. Evaporation loss is an important factor affecting the operating life of grease, and here it was performed by a grease and lubricant evaporation loss tester (DFYF-112, Dalian Analytical Instrument Factory, China) per ASTM D972-2002. In addition, anti- wear property of shield tail sealing grease is examined according to ASTM D2266-91, by means of the Four-Ball Wear Test Machine (Xiamen Tenkey Automation co. LTD, China), whose schematic diagram is shown in Fig. 3. 


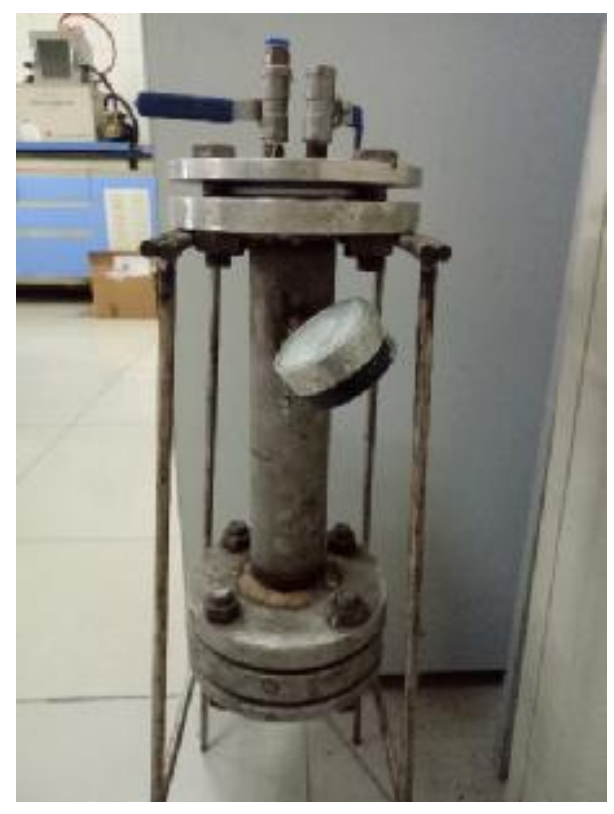

(a)

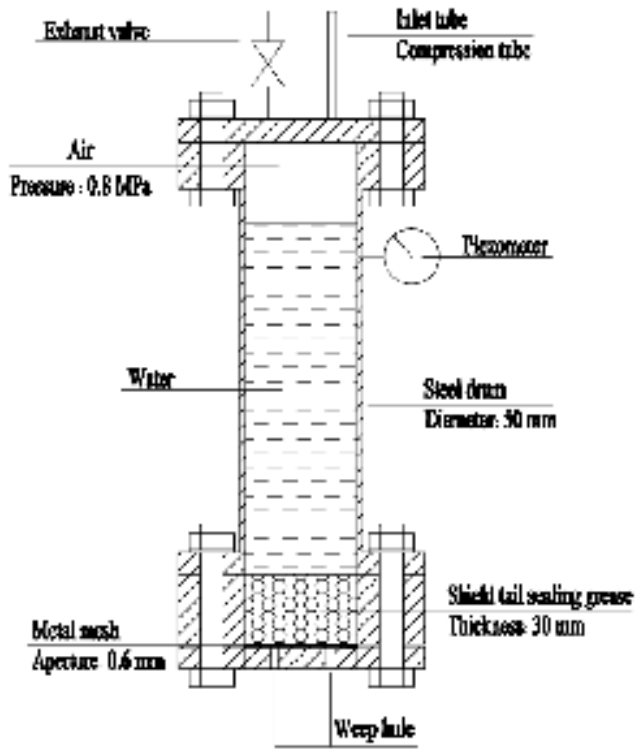

(b)

Fig. 2 Device for test on water-tightness of grease under high pressure
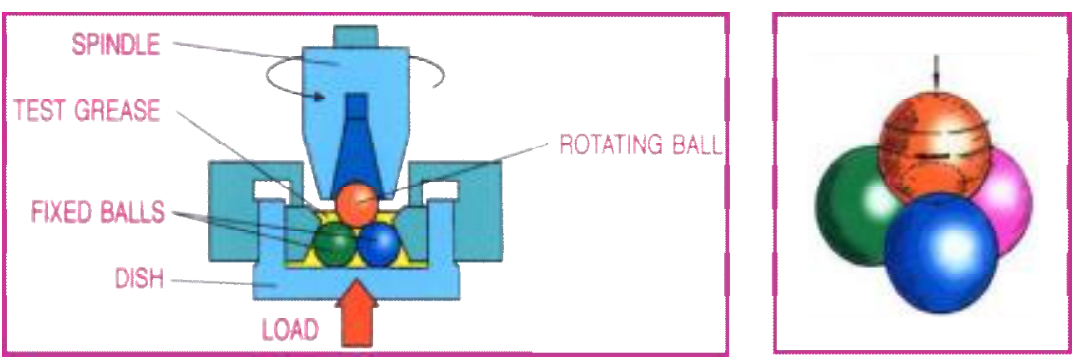

Fig. 3 Schematic diagram of the Four-Ball Wear Test Machine

\section{Results and discussion}

Density at the temperature of $25^{\circ} \mathrm{C}$ analysis. The results of densities at $25^{\circ} \mathrm{C}$ of all samples are illustrated in Table 3 . It is known that the density of some shield tail sealing grease is directly related to the amount of consumption, besides, the higher the density is, the worse the liquidity and pump delivery will be. Thus, density can be used as one of the indicators to evaluate pump delivery. In our study, it can be seen from Table 3 that densities vary little among different samples except for S0, generally within the range of $1.28-1.34 \mathrm{~g} / \mathrm{cm}^{3}$, which is comparable with that of some products proposed by other researchers $[9,11]$. Combined with Table 2, it is not difficult to find that the proportion of inorganic filler R6/R7 can obviously decrease the density by comparing S0 and S1. Meanwhile, by comprehensive comparison of S0-S10, it also shows the same tendency that reduced proportion of R6/R7 helps the reduction of density. In addition, other raw materials such as thickening agent (R2), lubricating grease thickener (R3) and fiber (R5) all effect density to different degrees, while less effect occur than the proportion of inorganic filler R6/R7. It also can be concluded from the results in this study that the appropriate proportion of R6/R7 for density is 0.7-1.2.

Table 3 Densities of the resultant sealing grease at $25^{\circ} \mathrm{C}$

\begin{tabular}{cccccccccccc}
\hline Sample number & S0 & S1 & S2 & S3 & S5 & S6 & S7 & S8 & S9 & S10 & S11 \\
\hline Density $\left[\mathrm{g} / \mathrm{cm}^{3}\right]$ & 1.40 & 1.33 & 1.31 & 1.30 & 1.30 & 1.34 & 1.30 & 1.29 & 1.32 & 1.30 & 1.28 \\
\hline
\end{tabular}

Cone penetration at the temperature of $25^{\circ} \mathrm{C}$ analysis. The results of cone penetration at $25^{\circ} \mathrm{C}$ are shown in Fig. 4. It has been reported that the evaluation index of shield tail sealing grease is 
usually between $220 \mathrm{~mm}$ and $250 \mathrm{~mm}$ [12], which is an appropriate range of sealing grease for pumping. Whereas, small cone penetration can indirectly indicate a poor pumping performance. In the present study, it can be seen from Fig. 3 that the cone penetration of S8, S9 and S10 is relatively qualified. This may be attributed to the reason that increasing the dosage of basic oil (R1) and conversely decreasing the dosage of thickening agent (R2) favors the promotion of cone penetration (Table 2).

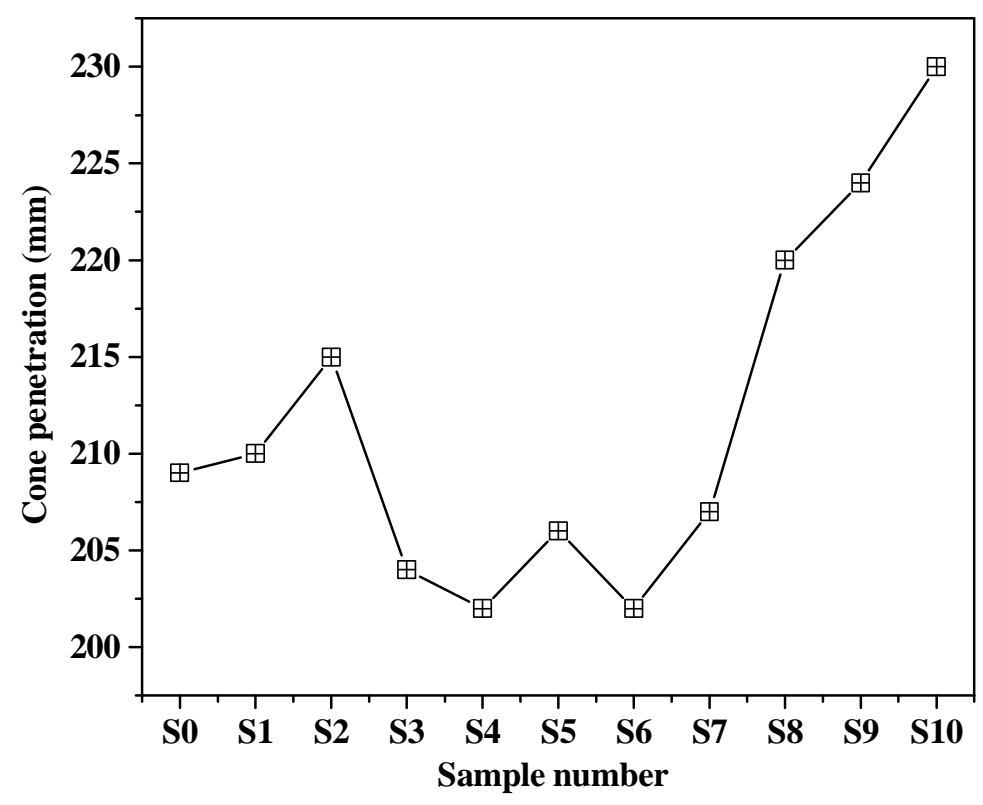

Fig. 4 Cone penetration of the resultant sealing grease

Water-tightness under high pressure analysis. For shield tail sealing grease, water-tightness under high pressure is a significant property. Here, Fig. 5 gives the holding time of all samples without water leakage under pressure of $0.8 \mathrm{MPa}$. The detailed test methods and evaluation of water-tightness of grease under high pressure of shield tail sealing grease in EFNARC and in USA are separately shown in Table 4 and Table 5. In our study, the holding time of the first three samples S0, S1 and S2 is not over $4 \mathrm{~min}$, while others all exceed $5 \mathrm{~min}$ and the longest holding time of S10 is even up to 9 min without water leakage. By reference to Table 4 and Table 5, it can be inferred that the first three samples have a poor water-tightness, on the contrary, other samples have relatively good water-tightness. The water-tightness under $0.8 \mathrm{MPa}$ pressure of S10 is extremely good, which may surpass the performance of foreign products. This indicates that the sample has a good adhesivity. It means that fiber (R5) as framework of sealing grease determinates the water-tightness, meanwhile, it can be concluded that when the dosage of fiber is over $6.4 \%$, a good water-tightness performance can be obtained (Table 2).

Table 4 Test conditions and evaluation of water-tightness of grease under high pressure of shield tail sealing grease in EFNARC [13]

\begin{tabular}{|c|c|c|}
\hline Sample level & test condition (air pressure $=0.8 \mathrm{MPa}$ ) & water-tightness of grease under high pressure \\
\hline A & $\begin{array}{l}\text { metal mesh with an aperture of } 1 \mathrm{~mm} \text {; } \\
\text { pressure holding time not less than } 5 \mathrm{~min}\end{array}$ & very good \\
\hline B & $\begin{array}{l}\text { metal mesh with an aperture of } 0.5 \mathrm{~mm} \text {; } \\
\text { pressure holding time not less than } 5 \mathrm{~min}\end{array}$ & good \\
\hline $\mathrm{C}$ & $\begin{array}{l}\text { metal mesh with an aperture of } 0.5 \mathrm{~mm} \text {; } \\
\text { pressure holding time less than } 5 \mathrm{~min}\end{array}$ & average \\
\hline
\end{tabular}


Table 5 Test conditions and evaluation of water-tightness of grease under high pressure of shield tail sealing grease of USP $[14,15]$

\begin{tabular}{ccc}
\hline $\begin{array}{c}\text { Sample } \\
\text { number }\end{array}$ & $\begin{array}{c}\text { outflow of water } V \\
{[\mathrm{~mL}]}\end{array}$ & $\begin{array}{c}\text { water-tightness of grease under high } \\
\text { pressure }\end{array}$ \\
\hline 1 & $V \leq 3$ & very good \\
2 & $3 \leq V \leq 10$ & good \\
3 & $V \geq 10$ & very poor \\
\hline
\end{tabular}

Test condition: air pressure $=0.8 \mathrm{MPa}$; aperture of metal mesh $=1 \mathrm{~mm}$; pressure holding time $=30$ $\min$

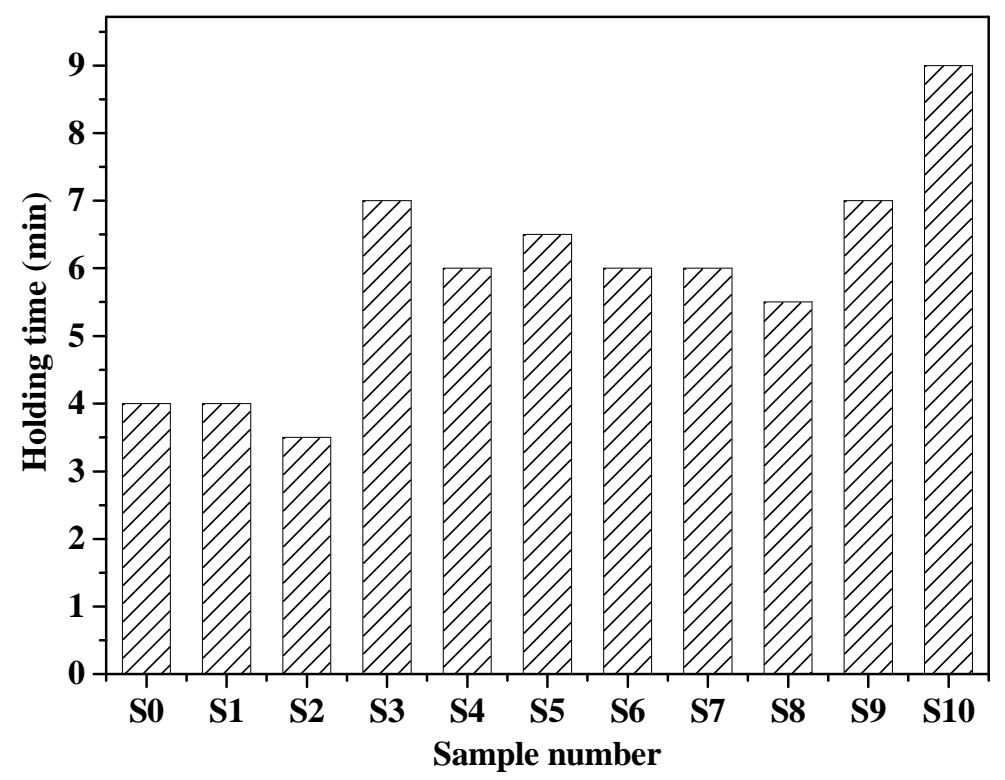

Fig. 5 Holding time of studied samples under pressure of $0.8 \mathrm{MPa}$

Resistance to water spray and evaporation loss analysis. Based on the previous results of density $\left(25^{\circ} \mathrm{C}\right)$, cone penetration $\left(25^{\circ} \mathrm{C}\right)$ and water-tightness under high pressure, it is found that $\mathrm{S} 8, \mathrm{~S} 9$ and S10 are qualified and have better performance. Therefore, their properties of resistance to water spray and evaporation loss are further studied. The results are illustrated in Table 6. It shows that the spay weightlessness and evaporation loss are all quite small, which means good water-resistant stability and stable ability at high temperature in sample S8, S9 and S10.

Table 6 Spray weightlessness and evaporation loss of studied samples

\begin{tabular}{ccccc}
\hline & $\mathrm{S} 8$ & $\mathrm{~S} 9$ & $\mathrm{~S} 10$ & evaluation index \\
\hline $\begin{array}{c}\text { spray weightlessness [\%] } \\
\left(38^{\circ} \mathrm{C}, 0.28 \mathrm{MPa}, 5 \mathrm{~min}\right)\end{array}$ & 0.7 & 0.9 & 1.2 & $\leqslant 7$ \\
$\begin{array}{c}\text { evaporation loss [\%] } \\
\left(80^{\circ} \mathrm{C}, 5 \mathrm{~h}\right)\end{array}$ & 0.15 & 0.25 & 0.27 & $\leqslant 2$ \\
\hline
\end{tabular}

Anti- wear properties. The anti-wear property of S10 is further investigated. Pictures of the scar area on the ball cup after continuous wearing captured by the matched microscope are displayed in Fig. 6. Fig. 6 a, b and c come from different angels of the same scar area on the same ball cup. As is shown, the pattern is not like a perfect circle no longer and occurs some grinding defect, which means there exist wear to some degree. The average diameter of wear scar is $0.51 \mathrm{~mm}$, and coefficient of friction is about 0.10 . This indicates that studied S10 has certain ability of resisting wear. It may be due to the more dosage of fiber in S10, which can enhance the bonding strength of raw materials and benefits the adhesivity of the sample. The results support former conclusion. 

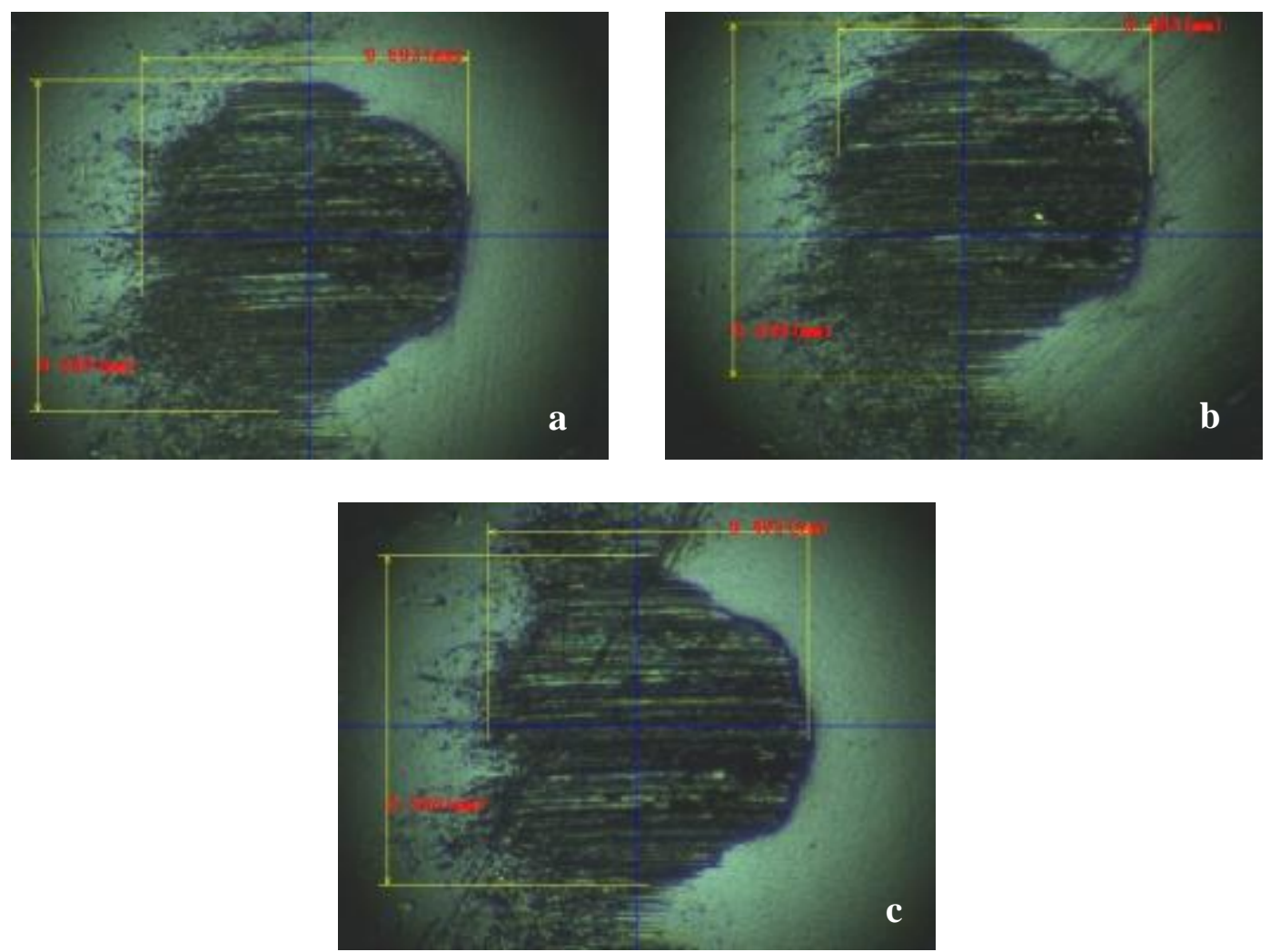

Fig. 6 Pictures of the scar area

\section{Conclusions}

From the present study, a type of shield tail seal grease has been preliminarily developed by means of a physical mixing process, using basic oil (R1), thickening agent (R2), lubricating grease thickener (R3), lubricating grease (R4), biodegradable fiber with a suitable toughness and length (R5) and inorganic fillers (R6 and R7).

The following major conclusions can be drawn:

(1) Inorganic fillers dominate the density $\left(25^{\circ} \mathrm{C}\right)$ of shield tail seal grease and the appropriate proportion of R6/R7 (0.7-1.2) can modify density in the range of $1.28-1.34 \mathrm{~g} / \mathrm{cm}^{3}$.

(2) By increasing the dosage of basic oil (R1) to $13.5 \mathrm{wt} . \%$, the cone penetration $\left(25^{\circ} \mathrm{C}\right)$ is improved and exceed $220 \mathrm{~mm}$.

(3) Biodegradable fiber (R5) has a great effect on the water-tightness under high pressure. A good water-tightness performance is obtained at the fiber dosage more than $6.4 \%$.

(4) Through previous results, prepared S8, S9 and S10 are qualified and have good properties of water-tightness under high pressure and pumpability characterized by density and con penetration, water-resistant stability and stable ability at high temperature. S10 has the best performance, of which density of $1.28 \mathrm{~g} / \mathrm{cm}^{3}$, cone penetration of $230 \mathrm{~mm}$ and as high as $9 \mathrm{~min}$ holding time are examined. Furthermore, there exists certain ability of resisting wear in S10, and the average diameter of wear scar is $0.51 \mathrm{~mm}$.

It can be deduced that shield tail sealing grease with good properties has been prepared in this study, and it also makes a strong foundation for further study and application of more effective shield tail sealing grease.

\section{Acknowledgements}

This work is supported by Shandong key Research and Development Plan (GG201703270077). Meanwhile, this work is supported by Department of Housing and Urban-Rural Development of Shandong Provice. 


\section{References}

[1] K.R. Hong: Tunn. Constr Vol. 33 (2013), p. 801

[2] K. Chen: Constr. Mechaniz Iss. (2) (2004), p. 58

[3] Z.H. Shi: Constr. Mac Iss. (5) (2005), p. 20

[4] M.J. Chen: Lub. Eng Vol. 35 (2010), p. 113

[5] D.Q. Wang: Tunn. Constr Vol. 33 (2013), p. 277

[6] D.Q. Wag: Rail. Constr. Technol Iss. (1) (2017), p. 7

[7] Z.X. Zhu: Chn. Build. WP (2009), p. 2

[8] C.H. Bai: Synthetic lubricants Vol 34 (2007), p. 23

[9] Y.T. Zhao. A kind of High Sealing Shield Grease and its Application, C.N. Patent, 201610832461 .4. (2016)

[10] X.S. Chen. Shield Seal Grease for Shield Tunneling Machine, C.N. Patent, 200910198379.0. (2009)

[11] D.Q. Wag: Rail. Constr. Technol Iss. (2) (2015), p. 86

[12] Z.L.Yan: J. S. TD. Univ Vol. 23 (2010), p. 91

[13] J. Washbourne. Sealing composition, Euro. Patent, 508719A1 (1992)

[14] P. Ellenberger, Feldmeilen (CH). Sealing Paste. U.S. Patent, 2012 /0037042 A (2012)

[15] Jacopo Franchini, Arese (IT). Tail Seals. U.S. Patent, 2011/0008107 A1 (2011) 